ORIGINAL ARTICLE

\title{
Strong correlation of maximal squat strength with sprint performance and vertical jump height in elite soccer players
}

\author{
U Wisløff, C Castagna, J Helgerud, R Jones, J Hoff
}

Br J Sports Med 2004;38:285-288. doi: 10.1136/bjsm.2002.002071

See end of article for authors' affiliations

Correspondence to: Dr Wisleff, Department of Circulation and Medical Imaging, Norwegian University of Science and Technology, Faculty of Medicine, Ólav Kyrres gt 3, N-7489 Trondheim Norway; Ulrik.Wisloff@ medisin.ntnu.no

Accepted 11 March 2003

\begin{abstract}
Background: A high level of strength is inherent in elite soccer play, but the relation between maximal strength and sprint and jumping performance has not been studied thoroughly.

Objective: To determine whether maximal strength correlates with sprint and vertical jump height in elite male soccer players.

Methods: Seventeen international male soccer players (mean (SD) age 25.8 (2.9) years, height 177.3 (4.1) cm, weight $76.5(7.6) \mathrm{kg}$, and maximal oxygen uptake $65.7(4.3) \mathrm{ml} / \mathrm{kg} / \mathrm{min}$ ) were tested for maximal strength in half squats and sprinting ability $(0-30 \mathrm{~m}$ and $10 \mathrm{~m}$ shuttle run sprint) and vertical jumping height.

Result: There was a strong correlation between maximal strength in half squats and sprint performance and jumping height.

Conclusions: Maximal strength in half squats determines sprint performance and jumping height in high level soccer players. High squat strength did not imply reduced maximal oxygen consumption. Elite soccer players should focus on maximal strength training, with emphasis on maximal mobilisation of concentric movements, which may improve their sprinting and jumping performance.
\end{abstract}

l: has been found that male elite soccer players cover $8-12 \mathrm{~km}$ during a game, depending on team role, ${ }^{1-3}$ nutritional status, ${ }^{45}$ and aerobic capacity. ${ }^{67}$ Within this aerobic context a sprint bout occurs about every 90 seconds, ${ }^{2}$ each lasting an average of two to four seconds. ${ }^{128}$ Sprinting constitutes $1-11 \%$ of the total distance covered in a match, ${ }^{12}$ corresponding to $0.5-3.0 \%$ of effective playing time-that is, the time when the ball is in play. ${ }^{1-10}$ Recently we showed that improvement in aerobic capacity in elite junior soccer players increased the distance covered, the play intensity, the number of sprints, and ball involvement during a game. ${ }^{7}$ Such findings highlight some of the advantages of a high aerobic capacity in soccer when related to actual performance.

During a game, professional soccer players perform about 50 turns, comprising sustained forceful contractions to maintain balance and control of the ball against defensive pressure. ${ }^{11}$ Hence, strength and power share importance with endurance in top level soccer play. Power is, in turn, heavily dependent on maximal strength, ${ }^{12}$ with an increase in the latter being connected with an improvement in relative strength and therefore with improvement in power abilities. A significant relation has also been observed between one repetition maximum (IRM) and acceleration and movement velocity. ${ }^{12}$ This maximal strength/power performance relation is supported by results from both jump and $30 \mathrm{~m}$ sprint tests. ${ }^{13}{ }^{14}$ Through inductive reasoning therefore, increasing the available force of muscular contraction in appropriate muscles or muscle groups may result in increased acceleration and speed in skills critical to soccer such as turning, sprinting, and changing pace. ${ }^{1}$ However, there is a lack of data on the relation between maximal strength and power performance such as sprint and jumping capacities in elite soccer players. Although such results can be logically deduced from the literature, there is at present little empirical support for such a supposition. The aim of this study was to determining the precise relation between strength and the dependent sprinting and jumping variables.

\section{METHODS}

\section{Subjects}

Seventeen elite male soccer players from Rosenborg FC (Trondheim, Norway) took part in the study, and performed all the tests described below. Rosenborg FC has been the most successful team in Norway over the past decade, winning the national league 11 times in a row, in addition to successfully competing in the UEFA Champions League tournament for eight successive years. The players studied were all full time professionals who trained on a daily basis. Their physical and physiological characteristics were as follows (mean (SD)): age 25.8 (2.9) years; height 177.3 (4.1) cm; weight 76.5 (7.6) kg; haemoglobin concentration in blood 160 (12) g/l; packed cell volume 0.463 (0.023); vital capacity (VC) 5.6 (1.0) litres; forced expiratory volume in one second $\left(\mathrm{FEV}_{1}\right) \quad 5.2$ (0.8) litres; $\mathrm{FEV}_{1} / \mathrm{VC} 92.9$ (3.0)\%; maximal heart rate 198 (17); maximal oxygen uptake $\left(\mathrm{VO}_{2} \mathrm{MAX}\right) 65.7$ (4.3) $\mathrm{ml} / \mathrm{kg} / \mathrm{min}$. Each subject reviewed and signed consent forms approved by the human research review committee before participating in the study.

\section{Procedure}

Day 1

Haemoglobin concentration, packed cell volume, and lung function were measured immediately for normative data comparisons. For determination of haemoglobin concentration and packed cell volume, blood was drawn from a fingertip and analysed immediately using the Refletron (Boehringer, Manheim, Germany) and Ames microspin (Bayer Diagnostic, Munich, Germany) appliances respectively. VC and $\mathrm{FEV}_{1}$ were determined using a flow screen (Jaeger, Friedberg, Germany). After these preliminary tests, the subjects completed a 20 minute warm up at $50-60 \%$ of $\mathrm{VO}_{2} \mathrm{MAX}$, before a free counter movement jump protocol was performed. Vertical jump height was determined using a

Abbreviations: IRM, one repetition maximum; VC, vital capacity; $\mathrm{FEV}_{1}$, forced expiratory volume in one second; $\mathrm{VO}_{2} \mathrm{MAX}$, maximal oxygen uptake 
force platform with specifically designed software (Bioware, Kistler, Switzerland). Jumping height was determined as the centre of mass displacement calculated from force development and measured body mass. Each player had three trials interspersed with a one minute rest between each jump. Only the best jump from each subject was used in data analysis. Immediately after this, the players were tested for a IRM half squat $\left(\sim 90^{\circ}\right.$ angle of the knee joints) performed with a competition standard Olympic style bar and weights (T-100G; Eleiko, Halmstad, Sweden). The players were familiar with half squats as part of their regular strength training programmes. Each player then performed 10 repetitions at low weights before gradually increasing the load to their maximum. The number of lifts before reaching IRM was three to six.

Twenty minutes after the strength test, each player ran for 10 minutes on a motorised treadmill (Challenger LE5000) at $50-60 \%$ of $\mathrm{VO}_{2} \mathrm{MAX}$. $\mathrm{VO}_{2} \mathrm{MAX}$ and maximal heart rate were then measured. In our laboratory, we routinely test $\mathrm{VO}_{2} \mathrm{MAX}$ after the strength test and obtain results that differ less than $\pm 2 \%$ compared with a $\mathrm{VO}_{2} \mathrm{MAX}$ test performed on a separate day-that is, within the accuracy of the recording system. The specific procedure for determination of $\mathrm{VO}_{2} \mathrm{MAX}$ and maximal heart rate was as previously documented. ${ }^{15}$ The speed of the treadmill was increased each minute to a level that brought the subject close to exhaustion after about five minutes. The inclination was constant at $3^{\circ}$. Immediately after $\mathrm{VO}_{2} \mathrm{MAX}$ determination, each subject ran for two minutes at an exercise intensity of $50-60 \%$ of $\mathrm{VO}_{2} \mathrm{MAX}$ which was, in turn, directly followed by a supramaximal intensity run, resulting in exhaustion after about three minutes. Heart rate was determined using short range radiotelemetry recording every five seconds (Polar Sporttester; Polar Electro, Oy, Finland). The highest heart frequency recorded during the last minute of the supramaximal intensity run was taken as reflective of maximal heart rate. Oxygen uptake, minute ventilation, and breathing frequency were measured continuously during exercise using an Ergo Oxyscreen (Jaeger EOS sprint).

\section{Day 2}

Three days after the tests to ascertain $\mathrm{VO}_{2} \mathrm{MAX}$, vertical jump height, and maximal strength, the players undertook a $30 \mathrm{~m}$ sprint test and a $10 \mathrm{~m}$ shuttle run test after a thorough 30 minute warm up. These tests were performed on an indoor handball field with a parquet floor; the players wore adapted indoor shoes. Times were recorded by photocells (Brower Timing, Fairlee, Vermont, USA) at the start lines, every $10 \mathrm{~m}$, and also at the finish lines of both tests. Each subject carried out two trials in each test separated by five minutes of rest. The subjects decided themselves when to start each test from a static position $30 \mathrm{~cm}$ behind the photocell, with the time being recorded from when the subjects intercepted the photocell beam. The best time taken to cover the $30 \mathrm{~m}$ distance in the sprint test was used in data analysis. The shuttle run test consisted of sprinting $10 \mathrm{~m}$ forward, around a cone placed between two photocells, and back to the finish-start line (photocells).

\section{Allometric scaling}

Comparisons between athletes on variables such as $\mathrm{VO}_{2} \mathrm{MAX}$ and maximal strength (lRM) are often made in terms of absolute measures (litres/min or $\mathrm{kg}$ ) or relative to body weight $(\mathrm{ml} / \mathrm{kg} / \mathrm{min}$ or $\mathrm{kg} / \mathrm{kg}$ body weight) even though both are acknowledged as being functionally imprecise..$^{16}$ The oxygen cost of running at a standard velocity does not increase in direct proportion to body mass, a condition also common to strength. Dimensional scaling suggests that comparisons between a small and bigger individuals should be expressed by kg body weight raised to the power of 0.67 as $\mathrm{ml} / \mathrm{kg}^{0.67} / \mathrm{min}$ or $\mathrm{kg} /(\mathrm{kg} \text { body weight })^{0.67} \cdot{ }^{15}{ }^{16}$ Based on empirical data, Helgerud ${ }^{15}$ found that comparisons of $\mathrm{VO}_{2} \mathrm{MAX}$ should be expressed relative to body mass raised to the power of 0.75 when running. If dimensional scaling is not used, both maximal relative strength and relative endurance will underestimate the big athlete and overestimate the small one. $^{16}$

\section{Statistical analysis}

Data are presented as mean (SD). To allow comparison of unrelated observations, the Kruskal-Wallis test was used, which includes appropriate procedures for multiple comparisons between groups. The Pearson product-moment correlation was also used to determine the relation between selected variables. $\mathrm{p}<0.05$ was considered significant.

\section{RESULTS}

The following results were obtained: $\mathrm{VO}_{2} \mathrm{MAX} 5.0(0.4)$ litres/ min, 65.7 (4.3) ml/kg/min, and 194 (10) $\mathrm{ml} / \mathrm{kg}^{0.75} / \mathrm{min}$; squats 171.7 (21.2) kg, $2.2(0.3) \mathrm{kg} / \mathrm{kg}$ body weight, and 9.4 (1.5) $\mathrm{kg} /(\mathrm{kg} \text { body weight })^{0.67}$; vertical jump 56.4 (4.0) cm; $10 \mathrm{~m}$ sprint $1.82(0.3)$ seconds; $20 \mathrm{~m}$ sprint 3.0 (0.3) seconds; $30 \mathrm{~m}$ sprint $4.0(0.2)$ seconds. The level of IRM correlated well with the $10 \mathrm{~m}$ sprint time $(r=0.94$, $\mathrm{p}<0.001$, fig 1A), $30 \mathrm{~m}$ sprint time $(r=0.71, \mathrm{p}<0.01$, fig $1 \mathrm{~B}), 10 \mathrm{~m}$ shuttle run $(r=0.68, \mathrm{p}<0.02$, fig $\mathrm{lC})$, and jumping height $(r=0.78, \mathrm{p}<0.02$, fig $1 \mathrm{D})$. Vertical jump height performance correlated with both $10 \mathrm{~m}(r=0.72$, $\mathrm{p}<0.001)$ and $30 \mathrm{~m}$ sprint time $(r=0.60, \mathrm{p}<0.01)$. The mean time taken for the $10 \mathrm{~m}$ shuttle run test was 4.34 (0.3) seconds, incorporating a mean 2.13 (0.2) second split time. No significant correlation was found between $10 \mathrm{~m}$ shuttle run time and $10-30 \mathrm{~m}$ sprint times. No positional differences were observed among players.

\section{DISCUSSION}

The results of this study confirm that a strong correlation exists between maximal strength, sprinting, and jumping performance in elite soccer players, which supports the findings from earlier work. ${ }^{12}{ }^{1320}$ The strongest correlations were found, as expected and echoing Newton's 2nd law of motion, where acceleration was greatest. There were also strong correlations between maximal strength and the $30 \mathrm{~m}$ sprint test, including the recorded times between 10 and $30 \mathrm{~m}$ where the acceleration is substantially smaller than between 0 and $10 \mathrm{~m}$, and the $10 \mathrm{~m}$ shuttle run test, where breaking velocity is part of the performance. Vertical jump height was in line with previous reports on elite soccer players, ${ }^{16}{ }^{17}$ and the relatively strong correlation between vertical jumping performance and sprint times was expected as both are derivatives of maximal strength.

It should be noted that at Rosenborg FC, strength training is performed on an individual basis without any supervised regimen from the coach. However, all players do perform half squats as part of their normal strength training programme. Nine of the players used in this study received additional advice from our research group and consequently integrated a strength training programme twice a week into their normal schedule. This involved using few repetitions with high loads and high velocity of movement as described below. These nine players had considerably higher IRM values than the other eight players. We have recently shown the effectiveness of such a training programme; increasing $1 R M$ in half squats by about $35 \%$ (from $160 \mathrm{~kg}$ to $215 \mathrm{~kg}$ ). The programme consists of five repetitions performed twice a week over a period of eight weeks, with the load being increased by $5 \mathrm{~kg}$ each time the athlete successfully 

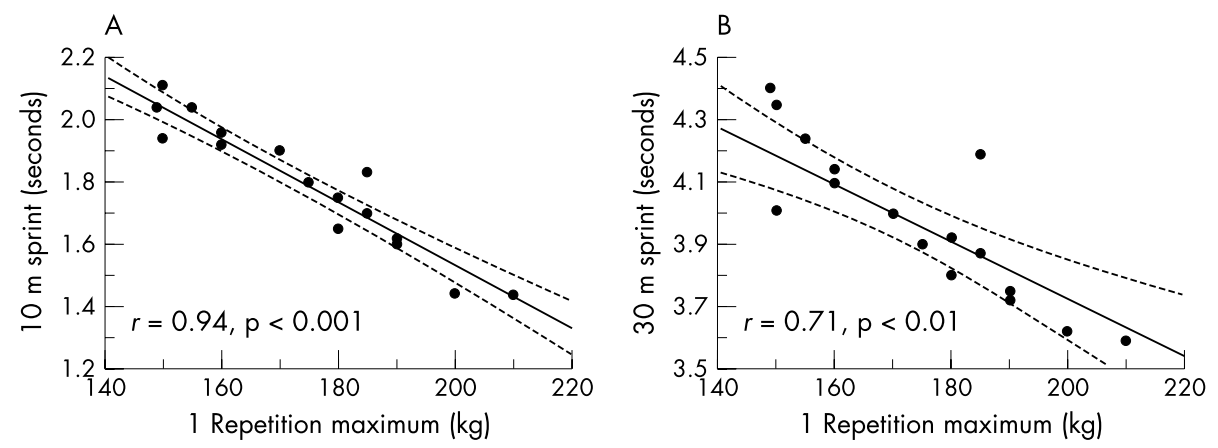

Figure 1 Relation between maximal strength in half squats and $10 \mathrm{~m}$ sprint (A), $30 \mathrm{~m}$ sprint (B), $10 \mathrm{~m}$ shuttle run

(C), and vertical jump height (D).
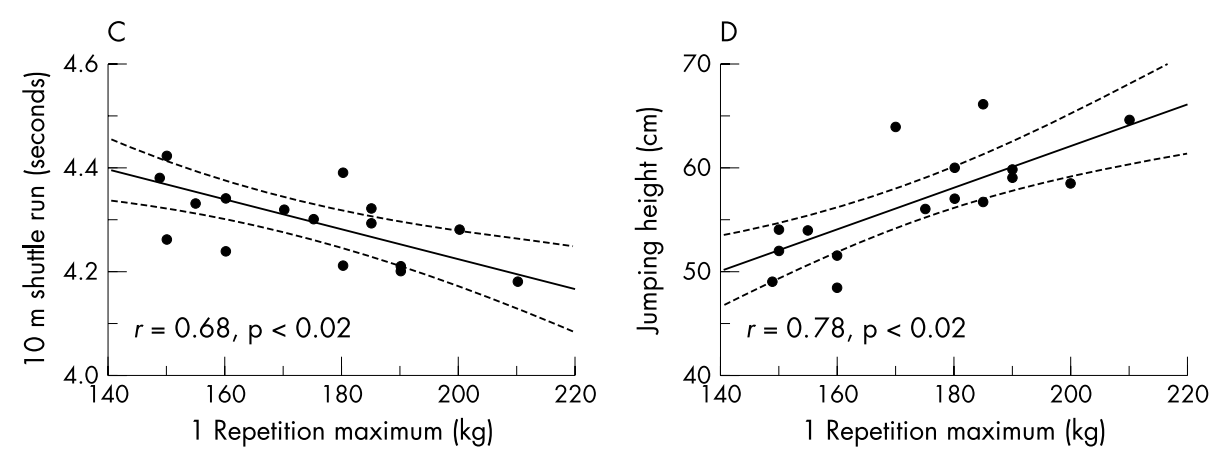

completes a weekly work load. ${ }^{14}$ A higher level of maximal strength and power in the "high strength" group is supposed to result in more powerful jumps, kicks, tackles, and sprints and reduce the risk of injury. ${ }^{13}{ }^{14}{ }^{16}$ As the high strength group had carried out a training regimen with emphasis on maximal mobilisation of force, which normally results in large training effects on rate of force development, it may mean that the correlation between maximal strength and all sprint and jump variables is not a global finding. Furthermore, it should be emphasised that the timing for the sprint test was from a moving position, starting $30 \mathrm{~cm}$ behind the photocell beam, which may have influenced the correlations observed.

If other training regimens for improving maximal strength are used as background for enhanced strength, the correlation with sprinting and jumping performance may be different. As no standardised protocol for testing strength of soccer players exists, it is difficult to compare results among different studies. In our view, commonly used isokinetic tests do not reflect the movement of the limbs involved during soccer. Tests using free barbells will reflect the functional strength of the soccer player more accurately. Furthermore, free barbells are readily available to most teams and provide the potential to develop a meaningful functional testing programme in conjunction with strength training. The result from IRM half squats in this study is in line with previous studies using free barbells. ${ }^{76^{17}}$ Both maximal strength and rate of force development are important factors in successful soccer performance because of the demands apparent from game play. ${ }^{2}$ Both should therefore be systematically worked on within a weekly schedule using few repetitions with high loads and high velocity of contraction as described elsewhere. ${ }^{13} 18-20$

A recent study reported that $96 \%$ of sprint bouts during a soccer game are shorter than $30 \mathrm{~m},{ }^{21}$ with $49 \%$ being less than $10 \mathrm{~m}$. The $30 \mathrm{~m}$ sprint times reported here were in line with earlier studies on elite soccer players. ${ }^{717}$ However, the data also show that there were substantial time differences within the $30 \mathrm{~m}$ test. In particular, two of the players had similar timed performances on the overall test, but significant differences between how they ran the first and the last part of the test. The implication is that it is possible to differentiate the focus of sprint training individually on the basis of split time recordings.

The present shuttle run/sprint test involved a sharp change in direction which tested the balance, strength, flexibility, breaking, and acceleration capacity of the players. In line with previous work, ${ }^{22}$ the results from the study indicated that there was no relation between the $10 \mathrm{~m}$ shuttle run and the $30 \mathrm{~m}$ sprint test. However, both sprint capacities are of importance in soccer, and our data show that both capacities should be included and evaluated in a sprint test battery of soccer players.

As reported in previous studies, ${ }^{16}{ }^{23}$ elite soccer players have high $\mathrm{VO}_{2}$ MAX. A $\mathrm{VO}_{2}$ MAX of $65.7 \mathrm{ml} / \mathrm{kg} / \mathrm{min}$ or $194 \mathrm{ml} / \mathrm{kg}^{0.75} /$ min as found in this study is in line with earlier work from our laboratory ${ }^{16}$ and others. ${ }^{24}$ In activities that involve dynamic work with large muscle mass, as in soccer, it is generally assumed that $\mathrm{VO}_{2} \mathrm{MAX}$ is primarily limited by maximal cardiac output. ${ }^{7}$ Interval training with a working intensity of $90-95 \%$ of maximal heart rate increases the maximal cardiac output. We have recently shown the effectiveness of such a training programme, increasing $\mathrm{VO}_{2} \mathrm{MAX}$ about $5 \mathrm{ml} / \mathrm{kg} / \mathrm{min}$ by interval training $(4 \times$ 4 minutes intervals, twice a week) for eight weeks in well trained elite junior soccer players. ${ }^{7}$ This led to several positive on field adaptations such as increased distance covered, intensity of play, number of sprints performed, and ball involvements, highlighting some of the advantages of increasing $\mathrm{VO}_{2} \mathrm{MAX}$ in soccer players. The results in this group of players showed that a high level of maximal strength did not compromise a high $\mathrm{VO}_{2} \mathrm{MAX}$.

It has been concluded from several studies that endurance training inhibits or interferes with strength development. Nelson $e a^{25}$ claimed that simultaneous training of strength and endurance inhibits the normal adaptation to either training regimen when performed alone. Thus up to a reasonably high level of both strength and endurance capacity, there seems to be little interference between training strength and endurance capacity simultaneously, which obviously have to be carried out in soccer as both capacities are needed. 


\section{Take home message}

Elite soccer players should focus on maximal strength training with emphasis on maximal mobilisation of concentric movements, which may improve their sprinting and jumping performance.

Rosenborg FC organises most of the endurance training purely as playing sessions, and satisfactory results are obtained in this way. It seems, however, that in sessions with few players on each side, such as five a side, there exists a ceiling effect around $65 \mathrm{ml} / \mathrm{kg} / \mathrm{min}$, which does not exist in running. ${ }^{26}$ Recently we showed that interval training with the ball may be as effective as pure uphill running (which normally is required to obtain high enough exercise intensity) when performed either on a dribbling track or as a supervised playing session. ${ }^{26}$ Monitoring the training intensity during a playing session, with the assistance of a heart rate monitor, will be helpful in this regard.

\section{Conclusions}

Maximal strength in half squats determined the sprint performance in these elite soccer players. Strong correlations are evident in all aspects of $0-30 \mathrm{~m}$ sprints as well as the $10 \mathrm{~m}$ shuttle run test and jumping height. The players with a high level of strength in this team had used a training regimen with few repetitions, high loads, and emphasis on maximal mobilisation of force in the concentric part of the half squat. High strength half squat performance does not imply a lower level of oxygen consumption in elite soccer players. Future research should involve the effect of maximal strength training on performance during soccer games.

\section{Authors' affiliations}

U Wisleff, J Helgerud, J Hoff, Department of Circulation and Medical Imaging, Norwegian University of Science and Technology, Trondheim, Norway

U Wisløff, Department of Cardiology, St Olavs Hosptal, Trondheim C Castagna, Research Department, Teknosport, Ancona, Italy

$R$ Jones, Department of Education, University of Bath, UK

\section{REFERENCES}

1 Bangsbo J, Nørregaard L, Thorsøe F. Activity profile of competition soccer. Can J Sport Sci 1991:110-16.
2 Reilly T, Thomas V. A motion analysis of work-rate in different positional roles in professional football match-play. Journal of Human Movement Studies 1976:87-97.

3 Reilly T. Motion analysis and physiological demands. In: Science and soccer. London: RTE \& FN Spon, 1996:65-79.

4 Saltin B. Metabolic fundamentals in exercise. Med Sci Sports Exerc 1973:137-46.

5 Jacobs IN, Westlin J, Karlsson M, et al. Muscle glycogen and diet in elite soccer players. Eur J Appl Physiol 1982:297-302.

6 Smaros G. Energy usage during football match. In: Proceedings of the First International Congress on Sports Medicine Applied to Football. Rome: L Vecchiet, 1980:795-801.

7 Helgerud J, Engen LC, Wisløff U, et al. Aerobic endurance training improves soccer performance. Med Sci Sports Exerc 2001;33:1925-31.

8 O'Donoghue P. Time-motion analysis of work rate in elite soccer. In: Notational analysis of sport IV. Porto: Centre for Team Sports Studies, Faculty of Sport Sciences and Physical Education, University of Porto/HM Tavares Fernanado, 2001:65-70.

9 Ali A, Farrally M. A computer-video aided time-motion analysis technique for match analysis. J Sports Med Phys Fitness 1991;31:82-8.

10 Bangsbo J. Time and motion characteristics of competiton soccer. Science and Football 1992:34-40.

11 Withers RT. Match analyses of Australian professional soccer players. Journal of Human Movement Studies 1982;8:159-76.

12 Bührle M, Schmidtbleicher D. Der einfluss von maximalkrafttraining auf die bewegungsschnelligkeit (The influence of maximum strength training on movement velocity). Leistungssport 1977;7:3-10.

13 Schmidtbleicher D. Training for power events. In: Komi PV, ed. Strength and power in sport. Oxford: Blackwell Scientific Publications, 1992:381-95.

14 Hoff J, Berdahl GO, Bråten S. Jumping height development and body weight considerations in ski jumping. In: Müller E, Schwameder $\mathrm{H}$, Raschner $\mathrm{C}$, et al, eds. Science and skiing II. Hamburg: Verlag Dr Kovac, 2001:403-12.

15 Helgerud J. Maximal oxygen uptake, anaerobic threshold and running economy in women and men with similar performances level in marathons. Eur J Appl Physiol 1994;68:155-61.

16 Wisløff U, Helgerud J, Hoff J. Strength and endurance of elite soccer players. Med Sci Sports Exerc 1998;30:462-7.

17 Hoff J. Training for rate of force development enhances running economy and aerobic performance. PhD thesis, Norwegian University of Science and Technology, Trondheim.

18 Sale DG. Neural adaptations to strength training. In: Komi PV, ed. Strength and power in sport. Oxford: Blackwell Scientific Publications, 1992:249-65.

19 Almaasbakk B, Hoff J. Coordination, the determinant of velocity. Specificity J Appl Physiol 1996;80:2046-52.

20 Hoff J, Almåsbakk $B$. The effects of maximum strength training on throwing velocity and muscle strength in female team-handball players. J Strength Cond Res 1995;9:255-8.

21 Valquer W, Barros TL, Sant'anna M. High intensity motion pattern analyses of Brazilian elite soccer players. In: IV World Congress of Notational Analysis of Sport. Porto: HM Tavares Fernanado, 1998:80.

22 Young WB, McDowell MH, Scarlett BJ. Specificity of sprint and agility training methods. J Strength Cond Res 2001;15:315-31.

23 Apor P. Successful formulae for fitness training. In: Reilly AL, Davids TK, Murphy WJ, eds. Science and football. London, New York: EF Spon, 1988:95-107.

24 Casajus JA. Seasonal variation in fitness variables in professional soccer players. J Sports Med Phys Fitness 2001:41:463-9.

25 Nelson AG, Arnall DA, Loy SF, et al. Consequences of combining strength and endurance training regimens. Phys Ther 1990;70:287-94.

26 Hoff J, Wisløff $U$, Engen LC, et al. Soccer specific aerobic endurance training. Br J Sports Med 2002;36:218-21. 